\title{
Planificación de la metodología docente adaptada al EEES: una propuesta en el ámbito de la economía aplicada
}

\section{Planning the teaching methodology adapted to EHEA: a proposal for Applied Economy subjects}

\author{
Antonio CALVO BERNARDINO y Ana Cristina MINGORANCE ARNÁIZ \\ Universidad San Pablo-CEU
}

Recibido: Abril 2012

Aceptado: Julio 2012

\section{Resumen}

La planificación y el trabajo en equipo en las unidades docentes, así como entre las mismas, resulta esencial en el desarrollo de metodologías de enseñanza adaptadas al EEES, especialmente cuando hay un perfil de alumno claramente definido que debe ser alcanzado. En este sentido, el presente trabajo, expone la experiencia de los miembros de la Unidad Docente de Política Económica y Sistema Financiero, y muestra el modo en que los mismos han coordinado las competencias, metodologías y sistemas de evaluación de las asignaturas que se integran dentro de la misma materia a fin de alcanzar el desarrollo de las competencias de una manera progresiva. Así mismo, se valora el esfuerzo, en horas de trabajo, que supone para los miembros de la unidad docente la aplicación de una metodología como la descrita.

Palabras clave: Metodología docente, Competencias, Planificación y coordinación, Esfuerzo profesores, Didáctica universitaria

\begin{abstract}
Application of teaching methods adapted to the EHEA requires planning and teamwork among teachers of the same subject, but also between teachers of different subject, especially when we have to achieve a student with specific skills. This paper describes the experience of professors who teach Economic Policy and Financial System, and shows how these have coordinated the skills, methodologies and evaluation systems in two different subjects in order to develop the skills in a progressive form. Also, it analyzes the effort, in hours of work, of teachers when they apply a methodology as we have described.
\end{abstract}

Keywords: Teaching methodology, Skills, Planning and coordination, Teachers effort, University pedagogy. 
Existe un riesgo en el contexto universitario actual, de que el proceso de enseñanzaaprendizaje ligado a los cambios pedagógicos, se acompañe de un sistema de evaluación que no sea acorde con las competencias que se pretenden desarrollar en los alumnos, como si evaluación y competencias fueran dos términos sin ningún tipo de conexión. Incluso yendo más allá, que algunas de las competencias fijadas, y que configuran el perfil del alumno que se desea formar, no lleguen a ser cubiertas en ninguna materia.

Por eso, para conseguir el perfil formativo perseguido es preciso que los estudiantes, no sólo consigan unas competencias acordes con el programa de la titulación que realizan, logradas de forma coordinada entre las distintas materias y cursos, sino que se acompañen de un sistema de evaluación que permita definir y medir su progresivo desarrollo.

En el presente artículo, ofrecemos una propuesta coordinada entre ambos elementos, competencias y evaluación, que sirva de ejemplo para la formación adecuada en una materia vinculada al ámbito de la economía y la empresa.

Para ello, en primer lugar, justificamos la necesaria planificación y coordinación que debe existir en los contenidos de los planes de estudio actuales; a continuación, establecemos la conveniencia de una estrecha relación entre las competencias a adquirir y el sistema seguido para evaluarlas; para, en tercer lugar, trasladar estos elementos a la práctica, mediante la definición de una materia, en la que determinaremos, siguiendo la línea argumental defendida, su metodología de enseñanza y aprendizaje, los sistemas de evaluación a emplear, así como la construcción del plan del curso y el trabajo, tanto presencial como autónomo, de los alumnos y de los profesores que se integran en una Unidad Docente.

\section{La planificación y la coordinación de contenidos en los Planes de Estudio}

El contexto universitario ha cambiado mucho en los últimos años fruto de la convergencia con el EEES, la necesidad de innovación, y, como afirma Giné (2009), del paso de una cultura en la que cada docente usaba en el aula las metodologías y los tipos de evaluación que más le convencían personalmente a otra en la que debe imponerse la coordinación entre los profesores que comparten asignaturas o materias.

Este proceso de cambio surge de la necesidad de formar en competencias, ofrecer una visión práctica a todo lo que hasta ahora era teórico, animar a los alumnos a asumir su protagonismo, garantizar su formación básica común y sustituir el sistema tradicional de evaluación por uno novedoso y variado. Todo ello hace que la actuación en equipo de los profesores se imponga como sistema de trabajo. Pero tan importante como eso, es la planificación y coordinación de todo el proceso de enseñanza y aprendizaje, planificación tanto a nivel de titulación como de curso, y por supuesto de asignatura (en este sentido véase Benito y Cruz (2005) y Calvo y Mingorance (2009)).

En relación con la planificación de la asignatura cabe indicar, en primer lugar, que la construcción de un espacio de aprendizaje es algo que no puede improvisarse, sino 
que requiere de una planificación que comienza con la determinación de las competencias que se pretende cubrir con ella ${ }^{1}$. Y esas competencias deben estar a su vez adecuadamente coordinadas con las perseguidas en el resto de asignaturas, logrando así una correcta estructura organizativa y formativa a nivel de titulación y en cada uno de los cursos que la componen; es decir, debe favorecerse la formación progresiva del alumno.

En definitiva, pues, el perfil del egresado se convierte en el punto de partida de la planificación y también de la coordinación, de manera que, cuando el alumno se gradúe, deberá haber adquirido todas las competencias establecidas en su titulación ${ }^{2}$. Sin embargo, es obvio que no todas podrán cubrirse en todas las asignaturas, siendo necesario establecer un reparto coherente entre las diferentes materias que el alumno deberá cursar, teniendo en cuenta que en los primeros años es muy probable que el peso de los conocimientos sea mayor que el de las capacidades, y la balanza se vaya decantando hacia éstas a medida que se avance de curso. Así, es necesario que en cada asignatura y curso se alcancen algunas competencias, siendo su consecución global el resultado de la agregación de los logros conseguidos en cada curso.

Una vez tomadas las decisiones en relación con las competencias a cubrir en cada materia, será posible adentrarnos en el diseño y planificación de la asignatura, para lo que es necesario definir, respetando en todo momento el mayor protagonismo del alumno dentro del aula, los métodos docentes que se seguirán a fin de lograr el desarrollo de las competencias en su máximo grado, así como los criterios de evaluación que permitirán determinar, de una manera justa y acorde a la metodología seguida, la obtención de las mismas (véase Delgado y Oliver (2006)) ${ }^{3}$.

La definición de la metodología a seguir debe respetar, no sólo las competencias a desarrollar, sino también las horas de esfuerzo total que, en línea con los ECTS de la asignatura, corresponde realizar al alumno medio para superar con éxito la misma. Estas horas totales deberán distribuirse, de una manera lógica y acorde a los métodos de aprendizaje que se hayan previsto, en trabajo presencial y no presencial, ya sea colaborativo o autónomo. De ahí la importancia de precisar cuáles son las tareas que

1 Aunque existen distintas definiciones de competencias, un resumen de las más significativas puede verse en Climent (2010).

${ }^{2}$ Se entiende por perfil del egresado el conjunto de conocimientos, habilidades y actitudes que conforman al alumno una capacidad para desenvolverse en las actividades laborales para las que se ha formado, y que constituyen el objetivo perseguido por el título realizado.

${ }^{3}$ Por metodología docente nos referimos a los métodos, recursos y formas de enseñanza que facilitan el éxito del proceso de enseñanza-aprendizaje, en concreto, la adquisición de competencias para aprender, desarrollar y conocer formas de poder seguir adquiriendo conocimientos en el futuro. En este sentido, la didáctica tradicional debe ser completada con una didáctica más actual donde lo interesante es saber por qué algo es así y cómo acceder a los conocimientos, y donde la evaluación es continua, permitiéndonos obtener un feedback para controlar y corregir la calidad y eficacia del aprendizaje y de los métodos y herramientas utilizados para tal fin. 
deberán realizarse, y de estimar el tiempo necesario para su realización con el fin de orientar el trabajo personal del estudiante.

Si bien, una planificación sin más no es suficiente; pues, en la medida en que se hace necesario cubrir todas las competencias, resulta imprescindible establecer con anterioridad a la iniciación del curso, un cronograma o plan del mismo, donde se recoja, sesión a sesión, el trabajo que se va a realizar en cada una de ellas, de modo que ninguna quede en el olvido por haber sido demasiado ambicioso y haber pretendido realizar más de lo que es posible. Del mismo modo, esta planificación nos ayudará a no dejar sesiones vacías de contenido. El cronograma resulta pues, tal y como se define, una herramienta muy útil para favorecer el aprendizaje continuo, pero también, para promover, tanto en el profesor como en el alumno, las competencias de responsabilidad y de compromiso que se hacen necesarias en todo proceso de aprendizaje. En este sentido, la planificación docente, además de requerir la programación del trabajo que deberá realizar el estudiante, ajustado al tiempo disponible, debe servir para estimar la carga de trabajo de los profesores.

En definitiva, la planificación de las asignaturas, cuyo proceso de construcción se muestra en la figura 1, deberá responder a una estructura lógica y ordenada, y se recogerá en la denominada guía docente (Parcerisa Arán (2008).

Figura 1.- Planificación de una asignatura y proceso de construcción de la guía docente

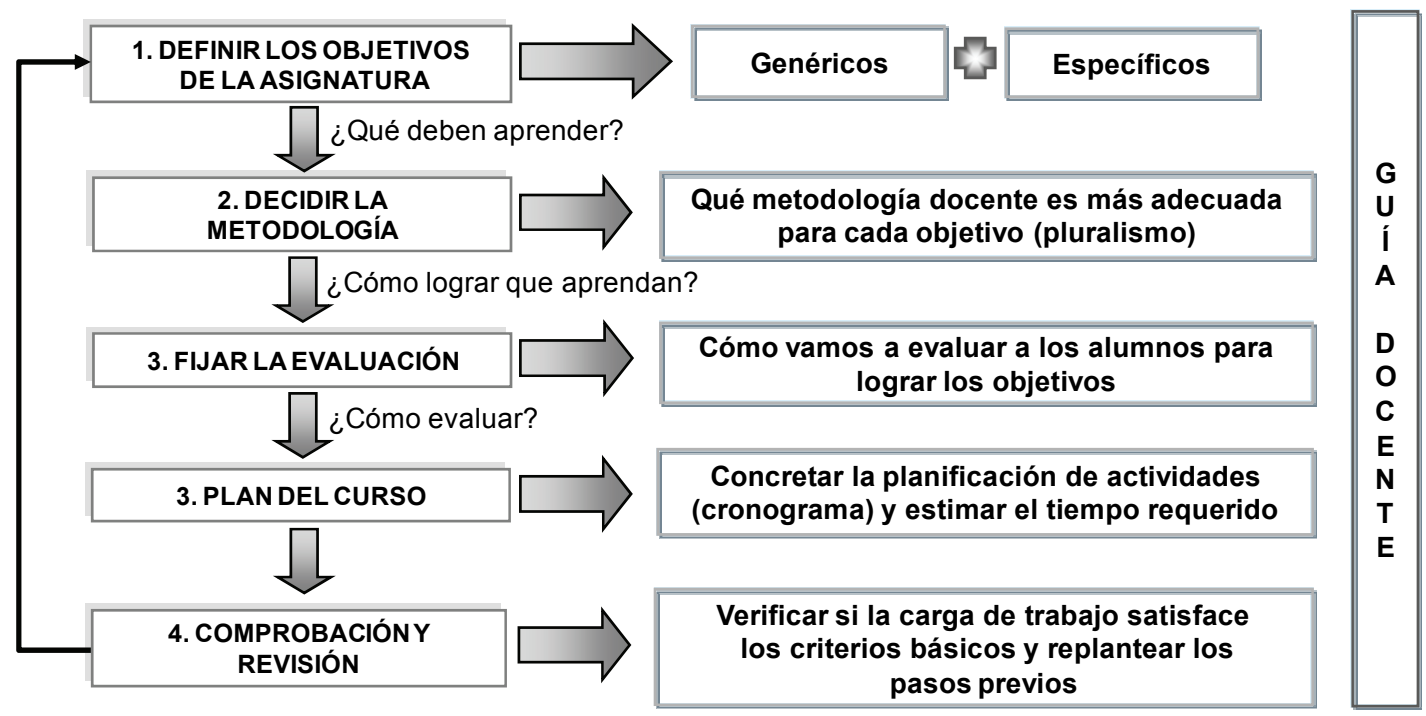

Fuente: Elaboración propia 
Esta guía docente cuenta, entre sus funciones principales, con la de orientar al alumno sobre lo que queremos que aprenda en la asignatura, cómo queremos que lo aprenda, y cómo se le va a evaluar, por lo que el primer día de clase debe estar a su disposición. Pero al mismo tiempo, la guía docente supone un compromiso entre el profesor y el alumno y deberá cumplirse, por lo que deberá ser realista, y no incluir competencias, metodologías o pruebas de evaluación que no se vayan a poder realizar al no contar con los espacios, los medios o los recursos humanos necesarios (véase Fernández March (2005 y 2006)).

La guía se convierte por tanto en un elemento esencial en la planificación de la asignatura, y deberá ser común para todos los miembros de la unidad docente, que deben coordinarse en su elaboración. Se hace así imprescindible, y como apunta Biggs (2006), potenciar los procesos cooperativos, que si se orientan adecuadamente, no se oponen a la autonomía del profesor, pues éste, cumpliendo siempre con lo acordado y establecido en la guía docente, debe mantener su propio criterio a la hora de fomentar el aprendizaje entre sus alumnos ${ }^{4}$. Así, se hacen necesarios docentes autónomos dentro de equipos con un sentido de responsabilidad colectiva (véase Rodríguez Izquierdo (2008)) $)^{5}$.

Por otro lado, la planificación y la colaboración no deben limitarse a una asignatura ni a los miembros de la unidad docente. Cuando se impone un sistema de evaluación continua y formativa es imprescindible planificar la carga de trabajo que el alumno deberá realizar a lo largo del curso en las diferentes asignaturas, con el objetivo de evitar la sobrecarga en momentos concretos del tiempo, y lograr una distribución temporal adecuada del mismo ${ }^{6}$. En este sentido, resulta imprescindible la labor de un coordinador de curso, el cual debe convocar las reuniones necesarias de los equipos docentes de su curso y elaborar un cronograma de distribución de las actividades a realizar en cada una de las asignaturas, así como de los elementos claves de la evaluación.

\footnotetext{
${ }^{4}$ Autonomía no debe interpretarse de ninguna manera como individualismo, pues en éste, como acertadamente señalan Yániz Álvarez de Eulate y Villardón (2006), existen zonas acotadas con pocas posibilidades de compartir recursos e ideas y de intercambiar experiencias, resultando ineficaz tanto para los estudiantes, al proporcionarles una formación fragmentada, como para el profesor, pues al igual que ocurre en el caso de los alumnos, el trabajo colaborativo mejora los resultados al facilitar el aprendizaje mutuo y aumentar la coherencia de los planteamientos educativos.

${ }^{5}$ Para Mayor Ruiz (2009), la mejora de la calidad docente exige que el trabajo colaborativo supere al individual, que la libertad de cátedra tenga un sentido enriquecedor y no de exclusión, y que se cuente con el apoyo de las autoridades académicas, potenciando, financiando y reconociendo los procesos de formación desarrollados por los profesores.

${ }^{6}$ Un análisis de los beneficios que supone contar con un coordinador de curso cuando la metodología de aprendizaje se centra en el alumno, y el sistema de evaluación, de carácter formativo, responde al trabajo continuo del mismo, puede consultarse en Esteve Pardo (2008) y Calvo y Mingorance (2009).
} 
Figura 2.- Procesos de coordinación vertical y horizontal de asignaturas

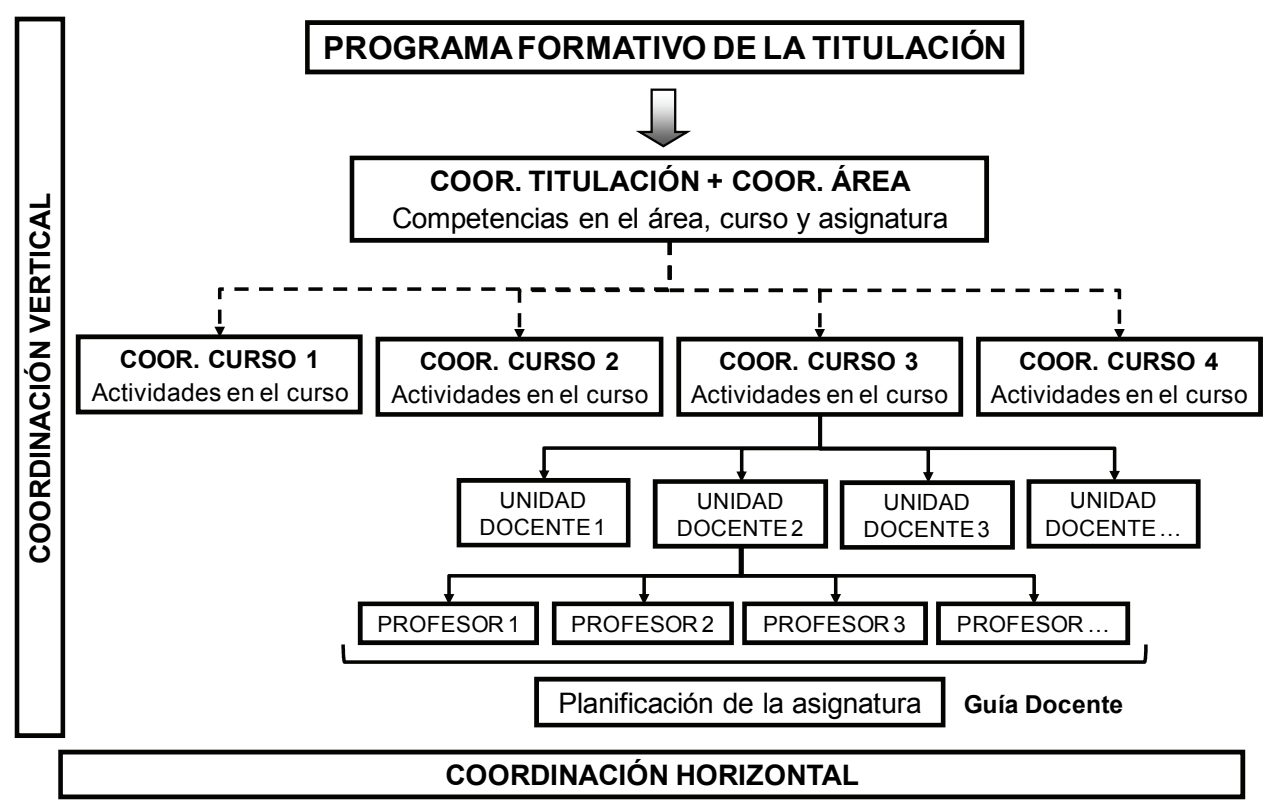

\section{Fuente: Elaboración propia}

En resumen, la constitución de equipos docentes, la existencia de responsables que sepan liderar el proceso de cambio metodológico y se conviertan en mentores de los profesores más jóvenes, la comunicación y el intercambio de ideas y experiencias y el apoyo de los órganos de gobierno del Centro y de los responsables de la titulación, se presentan como elementos esenciales para el éxito en la adaptación al EEES ${ }^{7}$. Es más, como se afirma en Moreno et al. (2010), ya no es suficiente con saber y saber comunicarlo, sino que el buen docente debe aprender a trabajar en equipo y a colaborar en la consecución de unos objetivos comunes para lograr el perfil de egresado que se desea. La coordinación horizontal y vertical, recogida en la figura 2, cobra pues fuerza y se muestra como elemento esencial en el proceso de enseñanza y aprendizaje.

\footnotetext{
${ }^{7}$ Un análisis detallado de las necesidades formativas de los profesores, en función de sus categorías académicas, para el éxito en la adaptación al EEES, que cuenta además con una bibliografía muy extensa, se realiza en VV.AA. (2011). 


\section{La evaluación de los alumnos en el marco de las competencias a desarrollar}

La evaluación es un proceso planificado que tiene por objeto la valoración del nivel de aprendizaje conseguido por el estudiante; cuya finalidad no es otorgar una nota, sino conseguir un aprendizaje y evaluarlo. En el marco de una evaluación de competencias, los métodos de evaluación establecidos en una materia o asignatura deben hacer referencia a la valoración que tendrá cada actividad en la calificación final de un alumno; de forma que, para determinar el sistema de evaluación hay que tener en cuenta las competencias fijadas en la materia y las que nos permite desarrollar la actividad, el tiempo y la dificultad de las actividades y la progresión en el aprendizaje.

Así pues, y como se describe en Calvo y Mingorance (2011), la evaluación debe ser un mecanismo para identificar si el alumno ha adquirido las competencias establecidas, pero, a su vez, debe permitir conocer los errores cometidos en el proceso formativo e introducir las mejoras necesarias, generar mecanismos de feedback con los alumnos para que su aprendizaje sea continuo a través de esas evaluaciones efectuadas, aumentar su motivación, y ayudarles a aplicar los principios teórico-abstractos adquiridos a contextos prácticos.

TABLA 1. RELACIÓN ENTRE LAS PRUEBAS A REALIZAR Y ALGUNAS DE LAS COMPETENCIAS QUE PERMITEN

\begin{tabular}{|c|c|c|c|}
\hline Tipo de prueba & Competencias & Tipo de prueba & Competencias \\
\hline \multirow{4}{*}{$\begin{array}{l}\text { Entrevistas entre } \\
\text { alumnos }\end{array}$} & 1. Conocimientos específicos & \multirow{4}{*}{$\begin{array}{l}\text { Búsqueda de } \\
\text { información }\end{array}$} & 1. Manejo de bases de datos específicas de la materia \\
\hline & 2. Creatividad e innovación & & 2. Análisis de la información bibliográfica \\
\hline & 3. Comunicación oral & & 3. Discernir la buena de la mala información \\
\hline & 4. Manejo de conflictos y negociación (liderazgo) & & 4. Uso de nuevas tecnologías \\
\hline \multirow{5}{*}{ Lecturas } & 1. Autoformación en temas relacionados con la materia & \multirow{5}{*}{ Talleres de discusión } & 1. Conocimientos específicos \\
\hline & 2. Conocimientos específicos & & 2. Capacidad de trabajo en equipo \\
\hline & 3. Capacidad de análisis & & 3. Capacidad de análisis y de presentación de ideas \\
\hline & 4. Comunicación escrita & & 4. Manejo de conflictos y negociación \\
\hline & 5. Capacidad de trabajo en equipo & & 5. Pensamiento crítico \\
\hline \multirow{4}{*}{ Actas de la sesión } & 1. Capacidad de sintesis & \multirow{8}{*}{ Proyectos } & 1. Conocimientos específicos \\
\hline & 2. Presentación formal de documentos & & 2. Capacidad de trabajo en equipo \\
\hline & 3. Preocupación por la calidad y mejora permanente del trabajo & & 3. Comunicación escrita y presentación formal de documentos \\
\hline & 4. Comunicación oral & & 4. Pensamiento crítico \\
\hline \multirow{4}{*}{$\begin{array}{c}\text { Exámenes abiertos } \\
\text { largos }\end{array}$} & 1. Conocimientos específicos & & 5. Aplicar los conocimientos de la materia a la práctica \\
\hline & $\begin{array}{l}\text { 2. Comunicación escrita (redacción coherente, ortografia, } \\
\text { vocabulario especializado) }\end{array}$ & & 6. Preocupación por la calidad y mejora permanente del trabajo \\
\hline & 3. Capacidad de razonamiento & & 7. Planificación y organización del trabajo \\
\hline & 4. Aplicar los conocimientos de la materia a la práctica & & 8. Responsabilidad \\
\hline \multirow{2}{*}{$\begin{array}{l}\text { Cuaderno de } \\
\text { vocabulario }\end{array}$} & 1. Conocimientos específicos & \multirow{5}{*}{ Panel de expertos } & 1. Búsqueda de información \\
\hline & 2. Aprender a buscar información & & 2. Conocimientos específicos \\
\hline \multirow{3}{*}{$\begin{array}{l}\text { Resolución de } \\
\text { problemas }\end{array}$} & 1. Conocimientos específicos & & 3. Capacidad de análisis y sintesis \\
\hline & 2. Capacidad de razonamiento & & 4. Comunicación oral y presentación de ideas \\
\hline & 3. Aplicar los conocimientos de la materia a la práctica & & 5. Responsabilidad en el aprendizaje \\
\hline \multirow{4}{*}{ Pósters } & 1. Conocimientos específicos & & \\
\hline & 2. Presentación de ideas & & \\
\hline & 3. Síntesis de la información & & \\
\hline & 4. Creatividad & & \\
\hline
\end{tabular}

Fuente: Elaboración propia a partir de Brown y Glasner (2007)

Por tanto, y siguiendo a Pallisera et al. (2010), el sistema de evaluación debe ser capaz de identificar los resultados del aprendizaje a partir de la selección de los 
contenidos conceptuales, procedimentales y actitudinales que integran cada competencia $^{8}$. Así, y como se menciona en Biggs (2006), una evaluación de competencias debe ser auténtica y general, y debe servir para comprobar el desenvolvimiento del estudiante en situaciones en las que resulta preciso aplicar los conceptos teóricos estudiados a realidades concretas, en definitiva, debe centrarse en lo que los alumnos han aprendido, y no tanto en el modo en que los docentes han enseñado. Aunque muchas de las competencias a alcanzar con el aprendizaje se pueden valorar a través de la realización de pruebas diversas, podríamos identificar, sin pretender ser exhaustivos, un conjunto de pruebas con algunas de las competencias que podrían identificar y evaluar (véase la tabla 1$)^{9}$.

Por otro lado, hay que tener en cuenta que de una misma competencia se pueden definir diferentes resultados de aprendizaje, diferentes aspectos implicados en la competencia o diferentes niveles de complejidad (véase Villa y Poblete (2006)). Y estas diferencias son el resultado de la formación progresiva que va logrando el alumno a medida que realiza materias y que avanza a lo largo de los cursos de una titulación.

Es por ello por lo que un adecuado desarrollo de las competencias a lo largo de un Grado exige una coordinación horizontal y vertical de las materias en la línea que habíamos señalado anteriormente, y como resume adecuadamente la figura 3.

Figura 3.- Proceso de transformación de las competencias en resultados de aprendizaje

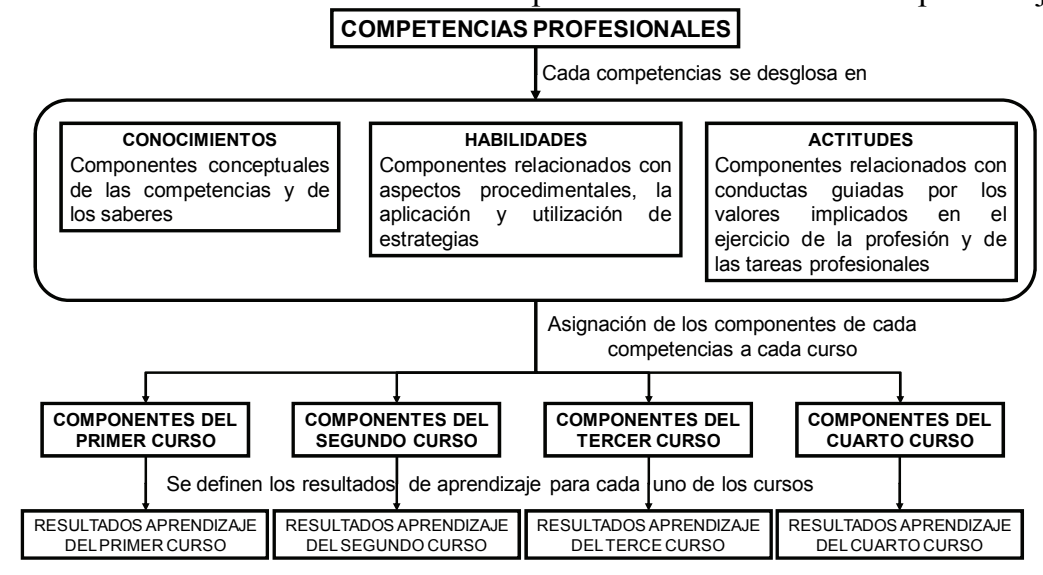

Fuente: Fullana (2009)

${ }^{8}$ La evaluación admite diferentes matices, así podemos hablar de evaluación en cuanto a la calidad del servicio educativo prestado, evaluación como procedimiento que mide el impacto de la actividad docente en los estudiantes, y evaluación como instrumentos de medición. Una adecuada combinación de todos ellos debe considerarse el objetivo a alcanzar.

${ }^{9}$ Debe tenerse presente que los ejemplos recogidos en la tabla 1 responden sólo a un diseño de las actividades a realizar. Así, una misma prueba podría ser válida para evaluar diferentes competencias en función del modo en el que la misma se diseñe. 


\section{La aplicación práctica de las competencias y su evaluación: análisis de un caso concreto}

\section{Definición de la materia elegida}

Una vez que hemos destacado la necesidad de la planificación y la coordinación de las materias integradas en una titulación con el objetivo de que permitan alcanzar las competencias definidas en el perfil del egresado; hemos señalado los caminos más adecuados para conseguirlo; hemos puesto de manifiesto también la importancia de que los métodos de evaluación utilizados sean acordes a esas competencias, lo que nos ha llevado a defender la utilización de métodos diversos; vamos ahora, en este apartado de nuestro trabajo, a transformar todas esas aportaciones teóricas a la realidad concreta de una materia o asignatura dentro de los planes de estudio vinculados con el ámbito de la economía y de la empresa.

En concreto, vamos a desarrollar todo lo referido a una asignatura del área de la economía aplicada $\mathrm{y}$, de acuerdo con nuestra especialización, al ámbito de la política económica y financiera ${ }^{10}$. De hecho, ésta es la denominación que vamos a utilizar, presentando la materia como una sola asignatura impartida en un único curso, aunque viendo primero los temas más relacionados con la Política Económica. Así, una vez que el alumno haya comprendido el proceso de toma de decisiones, el modo en que los objetivos de política económica se insertan en el esquema general de objetivos políticos, la articulación de los instrumentos para alcanzarlos, y los efectos de las medidas adoptadas, podremos avanzar en el análisis de la política financiera, y especialmente en el marco en el que se aplica el sistema financiero español.

Por otro lado, las competencias las plantearemos en todo momento de manera conjunta, y siendo conscientes de que la asignatura no puede formar parte ni del primer ni del segundo curso de la titulación, pues el alumno necesita haber adquirido previamente ciertas competencias que serán imprescindibles para su correcto seguimiento ${ }^{11}$. Este hecho nos beneficiará pues, tras dos años en el Grado, el alumno se habrá adaptado ya a una metodología docente tipo Bolonia y habrá realizado algunos

${ }^{10}$ La elección resulta, en nuestra opinión, muy interesante, pues el contexto actual de crisis en España tiene su piedra angular en los dos ámbitos de los que nos vamos a ocupar: la política económica, que no ha sido capaz de resolver, o al menos atender adecuadamente, los desequilibrios económicos de nuestro país y, en especial, el desempleo; y la política financiera que, dentro de aquella, cuenta con el sistema financiero, especialmente golpeado por la crisis. Por tanto, en un tema tan comprometido como es éste, fomentar el espíritu de diálogo y de crítica de los alumnos resulta, sin duda, muy interesante y enriquecedor, y justifica además la aplicación de metodologías docentes distintas, y sistemas de evaluación adaptados a ellas, también diferentes.

11 Entre ellos, unos conocimientos teóricos mínimos en economía y en métodos cuantitativos, que sea capaz de manejar algunas bases de datos de contenido económico, que utilice con cierta soltura los programas informáticos tradicionales, y que haya realizado algún trabajo en equipo. 
talleres de carácter práctico, lo que podremos aprovechar para desarrollar actividades más dinámicas.

En cuanto al sistema de evaluación, éste tendrá un carácter continuo, sumativo y formativo, lo que nos obligará a mantener una comunicación permanente con el alumno que le ayude a mejorar sus trabajos y su proceso de formación.

Dada la necesaria coordinación vertical en la titulación, y al tratarse de una materia de cursos superiores, en su inicio, y durante los primeros temas, utilizaremos una metodología adaptada al tipo de alumno recibido, e iremos transformándola, a medida que avance el año, en una más participativa y con mayor trabajo autónomo del alumno, de modo que al final del curso éste haya adquirido, no sólo las competencias que nos marquemos, y que consideramos esenciales en su formación, sino también una metodología de trabajo que resulte de utilidad para las asignaturas que le queden por realizar.

Por otra parte, su amplio contenido hará que la misma se distribuya a lo largo de todo el curso académico, y así, de los 15 ECTS de carga total, 10 corresponderán a la primera parte de la asignatura, política económica, y los 5 restantes, que se desarrollarán en el segundo semestre, a política financiera.

Partiendo de estas premisas iniciales, los siguientes pasos, para alcanzar la coherencia necesaria en nuestro planteamiento, serán, por este orden, plantear las competencias, la metodología y el sistema de evaluación.

\section{Competencias generales y especificas a desarrollar}

Un error muy habitual en muchas materias es la de elaborar proyectos ambiciosos que cubran un amplio número de competencias, incluyendo habilidades y actitudes, sin renunciar a los conocimientos que tradicionalmente se venían transmitiendo, complementando las sesiones formativas de carácter teórico con sesiones prácticas; en definitiva, sobrecargando la agenda tanto de profesores como de alumnos. Sin embargo, la racionalidad formativa nos debe llevar a marcar un avance progresivo y constante a lo largo del tiempo, consiguiendo el necesario equilibrio entre los conocimientos, las habilidades y las actitudes.

Respetando lo hasta ahora dicho, habría que establecer, en primer lugar, una diferencia entre las competencias generales y específicas que se deberán cubrir mediante actividades metodológicas concretas y la actitud de los miembros de la Unidad Docente.

Así, entre las competencias generales, resultan imprescindibles algunas habilidades y actitudes, como: ser capaz de organizar y planificar su propio trabajo a partir del cronograma y el plan de curso, aprender a trabajar en grupo, siendo conscientes de que la actitud de cada uno de los integrantes del mismo tiene efectos sobre todos los demás, lo que conllevará obligatoriamente a desarrollar en el alumno la madurez y responsabilidad propia de un estudiante de 20 años que en breve saldrá al mercado de trabajo. Junto a estas competencias, la honestidad, el compromiso ético y la capacidad de liderazgo son, a nuestro entender, las competencias que deberá adquirir cualquier 
profesional que pretenda afrontar su vida laboral con sentido de respeto y servicio a los demás.

Por otro lado tendremos las competencias específicas, que fijaremos teniendo en cuenta todas las adquiridas en los cursos previos ${ }^{12}$. Consideramos imprescindible la adquisición de conocimientos sobre los grandes objetivos e instrumentos de la política económica, así como la estructura y principales elementos del sistema financiero, a fin de que el alumno sea capaz de valorar, a la luz de los efectos de las medidas adoptadas, las decisiones del gobierno y de las autoridades monetarias, tanto desde un punto de vista cuantitativo como cualitativo. Junto a estos conocimientos se fijan algunas habilidades de carácter técnico y analítico. Entre las primeras incluimos, en primer lugar, el manejo de ciertas bases de datos específicas de la economía aplicada, pero también, gestionar la información, es decir, saber moverse y buscar información relacionada con la asignatura en la red. En segundo lugar, la capacidad de comunicar, tanto oralmente como de forma escrita, los conocimientos adquiridos y las reflexiones propias sobre las materias tratadas en la asignatura. No se trata sólo de saber expresar ideas y hacerlo de una manera fluida, destreza que debe adquirirse en los cursos previos, sino de aprender a comunicar ideas sobre la política económica y financiera, utilizando un lenguaje apropiado y unos argumentos económicos propios de un alumno del penúltimo curso del Grado (se busca, no sólo que exprese sus ideas, sino también que sepa defenderlas como si de un economista se tratase). Si bien, y para un adecuado desarrollo de la capacidad de comunicación, es conveniente que con carácter previo se le enseñe a sintetizar la información leída o escuchada, lo que le ayudará a organizar las ideas y a comunicarlas de una manera coherente.

En cuanto a las habilidades analiticas, el alumno debe ser capaz, al finalizar el curso, de discernir, apoyándose en los datos económicos, cuándo la situación económica de un país es la adecuada, y cuándo es necesario adoptar medidas que ayuden a corregir el comportamiento de alguna variable; en definitiva, se trata de enseñar a los alumnos a tomar decisiones que mejoren el bienestar de un país y ayuden a su crecimiento a medio y largo plazo. Si bien, es necesario que previamente el alumno sea capaz de enfrentarse a la información económica que se le facilita, así como de analizarla, acercándose a ella con una mente abierta que favorezca el razonamiento crítico.

Finalmente, entre los valores especificos que se pretenden inculcar al alumno, se encuentran la motivación por la calidad, no sólo de un trabajo bien hecho, sino también de la argumentación económica empleada en los razonamientos y justificaciones. Por otro lado, y muy vinculada a la anterior, el espíritu de superación, a través del aprendizaje de sus propios errores, y de los de los demás, y sobre todo, la necesidad de encontrar soluciones a los problemas planteados, lo que obliga a su continuo

12 Entre ellas, el uso de programas informáticos, la capacidad de comunicación oral y escrita, así como la de defender las ideas propias empleando para ello argumentos lógicos y racionales. Los conocimientos de estadística y determinados conceptos macroeconómicos resultan también imprescindibles. 
aprendizaje y formación. En el ámbito de nuestras materias, resulta también necesario que el alumno se adapte a trabajar en entornos de presión, ya no sólo porque en el mundo laboral al que deberá enfrentarse de inmediato esa presión existirá, sino también porque en la actividad económica la rapidez en la toma de decisiones puede ser una baza importante a nivel empresarial y global del país.

Con todas estas competencias, se pretende, en definitiva, favorecer la formación integral del alumno y desarrollar una nueva actitud hacia el aprendizaje y la construcción del conocimiento en el ámbito de la economía aplicada, enseñarle a superar los límites de tiempo y espacio, y hacerle sentir que a través de una actitud abierta y crítica, y mediante el trabajo colaborativo, se puede llegar a aprender lo que no se enseña en las aulas.

En la figura 4 se recoge un esquema de las competencias que acabamos de exponer.

Figura 4.- Esquema de competencias a desarrollar en la materia

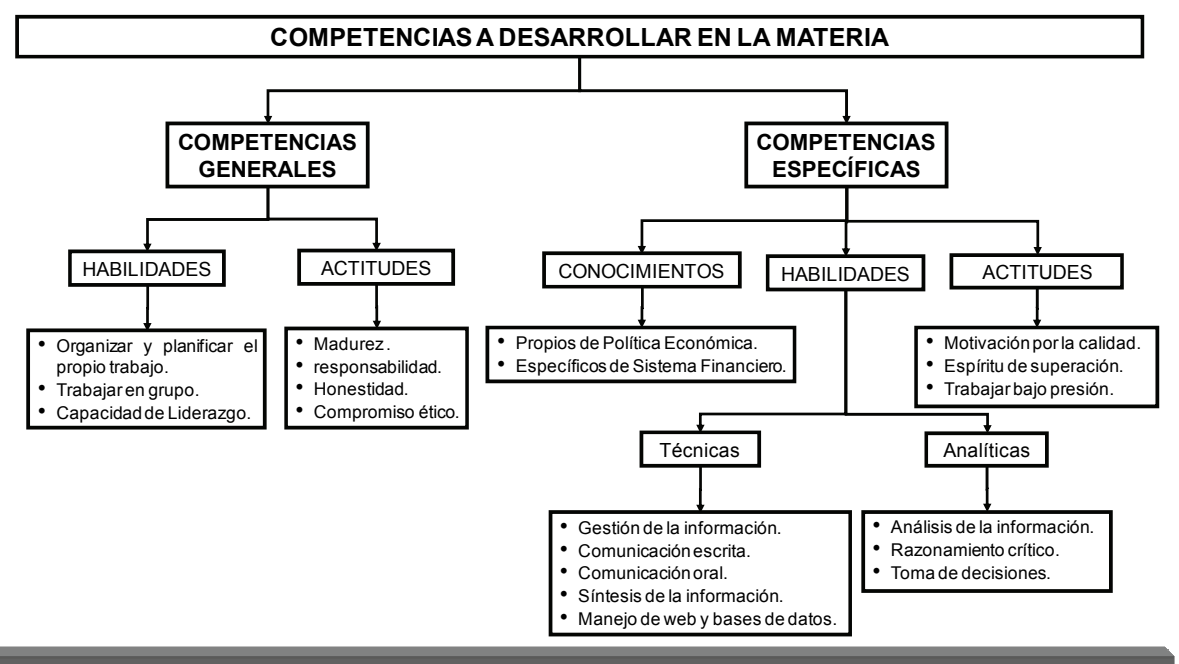

Fuente: Elaboración propia

\section{La metodología de enseñanza y aprendizaje empleada}

De acuerdo pues con las competencias establecidas, la metodología debe ser variada, incluyendo métodos docentes teóricos y prácticos. El esquema de trabajo en ambos semestres requiere dividir cada una de las partes de la materia en bloques. Así, en el primer semestre se establecerán tres bloques, cada uno centrado en una parte esencial de la política económica - conceptos iniciales, principales problemas, e instrumentos con los que cuentan los gobiernos para lograr los objetivos perseguidos. En el segundo semestre, cuando se trabaje la política financiera, el número de bloques será igualmente de 3 , dedicados a ofrecer una visión general de la política financiera y 
el Sistema Financiero Español, de los órganos de supervisión y sus funciones, y de los mercados financieros y los activos que en ellos se negocian, así como de las instituciones financieras.

Si bien, dado que nos hemos fijado una adquisición paulatina de competencias, se deben diseñar actividades diferentes para el primer y el segundo semestre, de modo que el alumno se vaya acostumbrando poco a poco a razonar con argumentos económicos y a aprender de manera autónoma. Para ello, contaremos con seminarios en los que descansarán las explicaciones teóricas de los contenidos básicos por parte del profesor. Mientras, las habilidades y actitudes, tanto generales como específicas, requerirán del empleo de metodologías muy variadas, y mientras los seminarios nos ayudarán a conseguir algunas, será necesario recurrir a otro tipo de actividades que permitan alcanzar las que no se puedan lograr mediante ellos.

Durante la primera parte de la materia será necesario crear el ambiente de trabajo adecuado, así como desarrollar en el alumno las inquietudes necesarias para lograr el desempeño de ciertas habilidades. Si bien, es posible que el grado de madurez alcanzado por el alumno, tanto a nivel personal como profesional, sea todavía insuficiente para desarrollar un trabajo totalmente autónomo, debiendo ser el apoyo del profesor importante. En concreto se plantean tres tipos de actividades, adicionales a los seminarios, en las que la dirección del profesor es pieza clave. En primer lugar, y para favorecer el razonamiento crítico, y ayudar al alumno a expresar oralmente ideas económicas, se abrirán sesiones semanales de exposición de noticias de actualidad de no más de 10 minutos de duración. Esta actividad, a realizar en parejas, supondrá también un primer acercamiento al trabajo en equipo, y ayudará al desarrollo de la responsabilidad y al compromiso ético que nos hemos fijado.

En segundo lugar, y para promover en el alumno el manejo de la información en páginas web, así como de bases de datos de contenido económico, o enseñarle a comunicar de manera escrita ideas económicas, se realizarán talleres de contenido práctico a modo de proyecto ${ }^{13}$. El carácter de proyecto que pretendemos dar al trabajo requerirá de un seguimiento permanente y de una corrección personal del trabajo presentado por los alumnos. Para ello, es preciso efectuar sesiones de tutorías académicas a las que asistirán, de manera conjunta, los grupos a los que se les haya asignado el mismo país de análisis (no más de cuatro grupos), y en las que se analizarán y revisarán los primeros borradores parciales de esos trabajos. Tras ellas, los alumnos deberán corregir los fallos cometidos, y complementar, con las valoraciones del profesor y del resto de grupos, sus trabajos, que deberán integrarse junto con el resto de entregas parciales, en un único documento o proyecto final para su evaluación. No obstante, las entregas parciales, así como el trabajo desarrollado durante la tutoría conjunta, también deberán ser objeto de evaluación. La motivación por la calidad y el

${ }^{13}$ El proyecto consistiría en hacer un seguimiento de la situación económica de los países, así como de las medidas en ellos aplicadas. A cada grupo de 3 o 4 alumnos se le asigna un país, y el profesor plantearía algunas preguntas generales que los grupos deberían responder a la vista del seguimiento realizado a su país. 
espíritu de superación se presentan como actitudes a promover bajo esta metodología de trabajo.

La formación de este primer semestre se debe complementar con alguna aportación externa, a modo de conferencia para cerrar el segundo bloque, y una lección magistral, a cargo del responsable de la Unidad Docente, en la que se ofrecerá una visión de conjunto de la Política Económica, y que servirá para sintetizar las ideas esenciales del semestre.

En el segundo semestre, cuando el alumno haya adquirido ya ciertos conocimientos, así como algunas habilidades y haya demostrado una cierta madurez, podremos permitirle cierta libertad de elección en su propia formación. En la segunda parte de la materia, la metodología de enseñanza y aprendizaje de cada bloque contará con una lección magistral, un conjunto de seminarios, y una tutoría conjunta y taller. Las lecciones magistrales se impartirán al comienzo del bloque a fin de situar al alumno en los temas que serán objeto de un desarrollo más profundo en los seminarios, y nos servirán para favorecer la gestión y síntesis de la información escuchada. Por su parte, las tutorías conjuntas y talleres requieren que cada profesor ofrezca un tema diferente de taller a realizar, vinculado siempre a los analizados en el bloque en el que el mismo tenga lugar, con tres horarios alternativos, de modo que el alumno se matriculará, en cada uno de los bloques, y siempre en los plazos señalados por la Unidad Docente, del taller que considere más adecuado para su formación, lo que sin duda ayudará a fomentar su autonomía. Durante la tutoría, común a todos los alumnos matriculados de un mismo taller, el profesor expondrá algunos conceptos básicos, así como las ideas generales del trabajo a desarrollar, al tiempo que comentará la metodología de trabajo del taller y el sistema de evaluación, que podrán variar de unos talleres a otros y entre profesores en función de las competencias en las que se desee profundizar, pero siempre dentro de los criterios fijados por la Unidad Docente (trabajo en grupo, presentación de documentos escritos, presentación oral o debate e intercambio de ideas entre los grupos...). El motivo se debe a la necesidad de desarrollar en los alumnos las competencias fijadas al diseñar la materia. Entre ellas, la comunicación escrita y la síntesis de la información trabajada, así como la toma de decisiones económicas, apoyadas siempre en argumentos económicos construidos de manera lógica y ordenada.

Por su parte, el propio sistema metodológico seguido a lo largo del curso será válido para enseñarles a organizar y planificar su trabajo, madurar y aprender a responsabilizarse de su propio aprendizaje, así como para afrontar el trabajo bajo el sistema de presión propio de la economía, donde la agilidad en la toma de decisiones puede resultar decisiva.

En la figura 5 se muestra, de forma resumida, la metodología de trabajo a seguir en cada uno de los semestres en los que se divide la materia. 


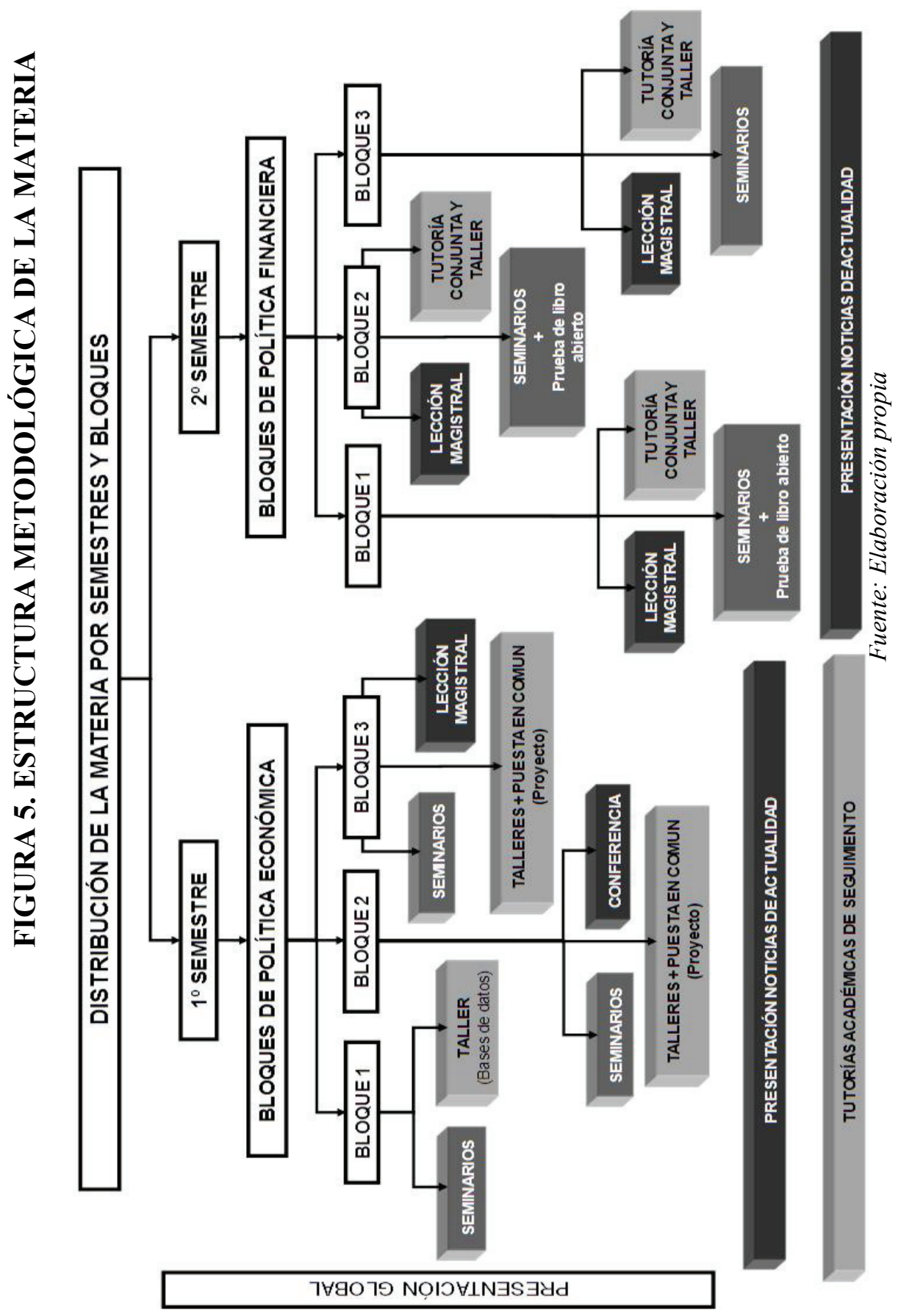




\section{El sistema de evaluación a emplear}

Una metodología como la descrita requiere de un adecuado sistema de evaluación ajustado a las horas de esfuerzo correspondientes a los 15 ECTS con los que cuenta la materia, y que permita conocer el grado de desarrollo de las competencias por parte de los alumnos. El sistema de evaluación debe integrarse en el propio proceso formativo, de modo que la definición del sistema de evaluación y de la metodología vayan a la par a fin de poder encajar adecuadamente todas las piezas.

La realización de los tradicionales exámenes de conocimiento debe complementarse con actividades adicionales, si bien a cada una de ellas debe dársele el peso adecuado en función de la importancia otorgada a las competencias que ayudan a desarrollar. Comenzaremos analizando el sistema de evaluación que se seguirá en cada metodología de trabajo, para posteriormente mostrar las competencias que nos permiten alcanzar cada actividad evaluativa, y cerrar con la participación de cada actividad en la nota final del alumno.

Durante el primer semestre los seminarios se evaluarán con una prueba escrita de desarrollo, una al final de cada bloque, de carácter liberatorio siempre que se alcancen los 4 puntos sobre 10. Por su parte, en el segundo semestre se realizarán dos pruebas escritas de conocimiento una de los bloques 1 y 2 , y otra del tercero. Asimismo, y para no parcelar la materia es conveniente efectuar una prueba tipo test al cierre de cada semestre que abarque todos los contenidos analizados en los seminarios y a la que deberán presentarse todos los alumnos. Por su parte, el día de la prueba test se permitirá, que los alumnos que no liberen alguna de las partes, la repitan, si bien, la calificación obtenida deberá hacer media con la lograda en el examen previo del bloque correspondiente para imprimir al sistema de evaluación una mayor continuidad.

Por su parte, el proyecto, a efectuar durante el primer semestre, exigirá un análisis tanto del trabajo realizado dentro del aula como de las entregas parciales que deberán hacerse. Una vez evaluado el trabajo escrito, se mantendrá con los alumnos un feedback dentro de las tutorías académicas de seguimiento, que permitirá a los grupos, tras la presentación de su trabajo, debatir con otros grupos que han analizado su mismo país, así como recibir las impresiones de su tutor, derivadas tanto del trabajo como de la exposición, lo que les servirá para corregir y mejorar las diferentes partes antes de integrarlas para la entrega final.

La evaluación se complementará con la exposición de noticias de actualidad, con la que se pretende que los alumnos se acerquen a la realidad económica de los países, de sus problemas y de las medidas adoptadas por las diferentes instituciones económicas y financieras. En concreto, un grupo por semana, comenzando desde el mismo momento en que se inicie el segundo bloque de cada semestre, hará un seguimiento de la prensa económica y expondrá un resumen de las noticias más sobresalientes.

Por su parte, y con el objetivo de enseñar a los alumnos el manejo de las bases de datos que necesitarán usar a lo largo de la materia, durante el primer bloque del primer semestre, se organizará un taller de bases de datos en el que los alumnos deberán descargar series de variables económicas y hacer los gráficos que se les indique, 
siempre de carácter básico y teniendo en cuenta los conocimientos adquiridos en los cursos previos.

La conferencia del experto se evaluará a partir del resumen que se pedirá a los alumnos que elaboren de forma individual, y en el que deberán sintetizar los aspectos más importantes tratados en la misma.

En el segundo semestre se realizan dos pruebas a libro abierto en las que el alumno, de forma individual, deberá responder a una serie de cuestiones relacionadas con un material que previamente habrá tenido que trabajar. Asimismo, las lecciones magistrales que abrirán cada bloque, se evaluarán mediante un cuestionario tipo test sobre los principales aspectos tratados.

En la tabla 2 se recoge, a modo de resumen, las competencias que cada una de las actividades diseñadas permite desarrollar, siendo el aprendizaje autónomo el objetivo último de la metodología seguida, y a cuyo logro contribuirán todas ellas.

\section{TABLA 2.- COMPETENCIAS ALCANZADAS CON LAS PRUEBAS DE EVALUACIÓN CONTINUA}

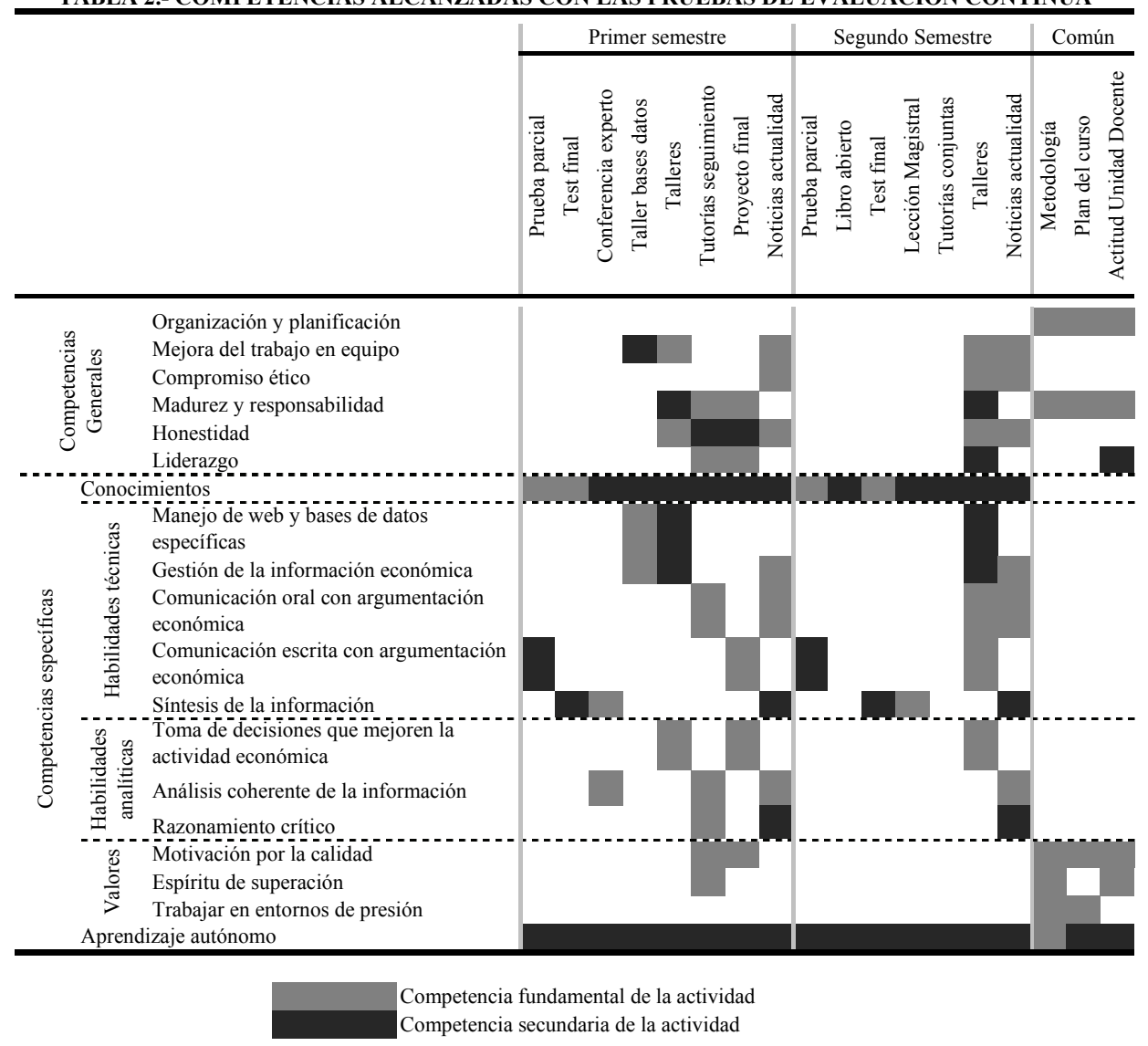

\section{Fuente: Elaboración propia}




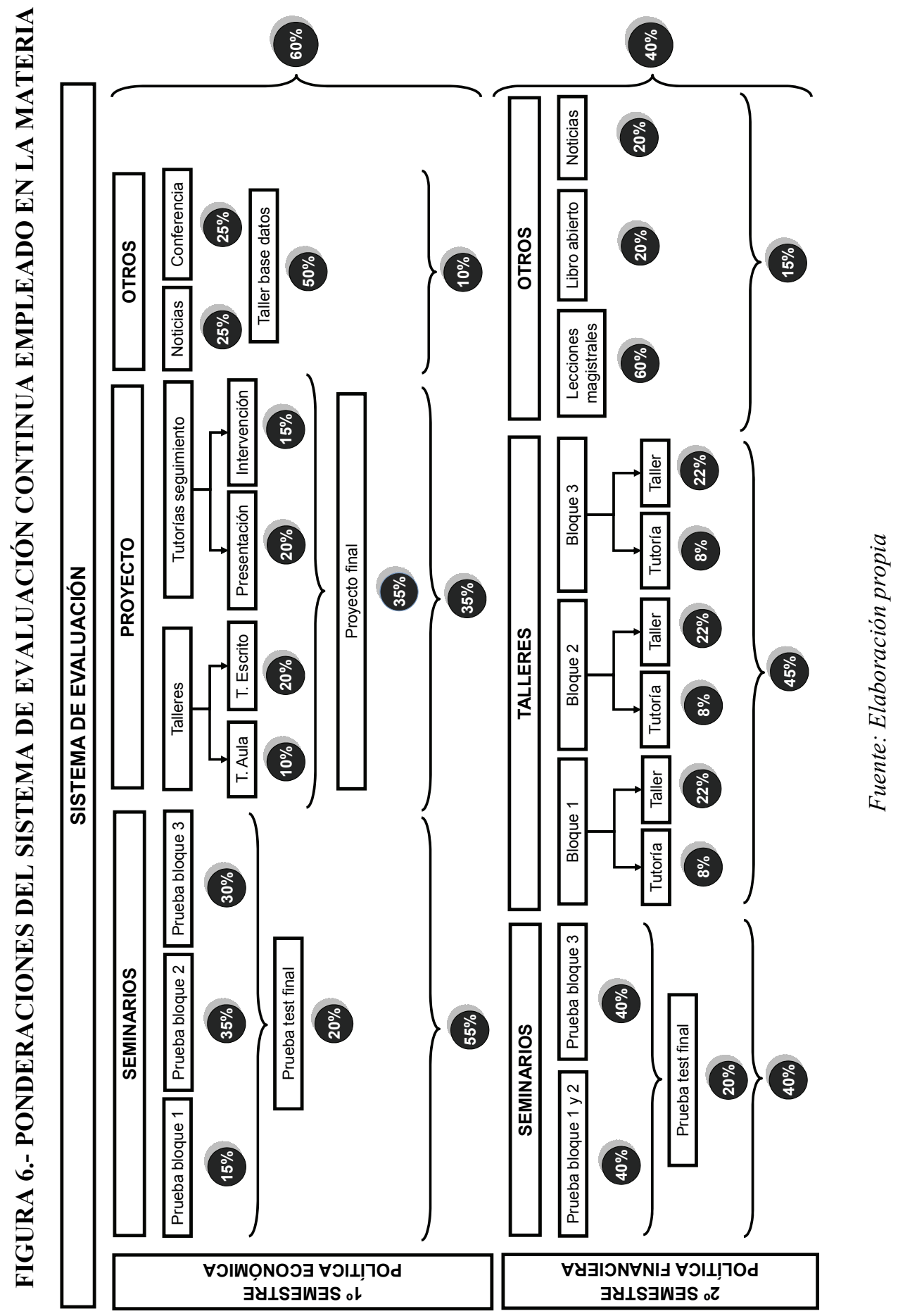


Por su parte, el peso de cada actividad en la calificación final del alumno debe guardar relación, como se mencionó al principio, con las competencias que nos permite evaluar, el esfuerzo que su superación exige al alumno, y el momento en el que la misma se realiza, buscando favorecer la formación progresiva. Por eso, mientras el primer semestre, con 10 ECTS ponderará un $60 \%$ en la nota final, el segundo semestre, con sólo 5 ECTS, lo hará en un $40 \%$. Además, y como se observa en la figura 6 , la importancia de la parte teórica y práctica cambia de un semestre a otro; así, mientras en el primero lo fundamental es que el alumno aprenda ciertos conocimientos sobre la economía aplicada, en el segundo se considera más importante el desarrollo de habilidades en las que se introducirá al alumno poco a poco mediante actividades prácticas. Por este motivo, el peso de los seminarios (pruebas de desarrollo y test final), será del $55 \%$ en el primer semestre, y sólo del $40 \%$ en el segundo. Por otro lado, la realización del proyecto del primer semestre, incluyendo en él los talleres, las tutorías de seguimiento y el proyecto final; y las tutorías conjuntas y talleres del segundo, será el otro componente importante de la nota final del alumno. Mientras el proyecto supondrá el $35 \%$ de la nota del primer semestre, las tutorías conjuntas y talleres serán el $45 \%$ de la del segundo; así quedan un $10 \%$ y un $15 \%$ en el primer y segundo semestre respectivamente para el resto de actividades realizadas.

Se ha diseñado un conjunto de actividades, lo suficientemente amplio, como para cubrir todas las competencias que en un principio nos habíamos fijado, y que creemos que un alumno del penúltimo curso del grado de economía o empresa debe adquirir. Asimismo, y primando el proceso de construcción y progresión que debe imperar siempre en un sistema educativo, hemos optado por dar mayor importancia a los conocimientos y a las destrezas más sencillas en la primera parte de la materia, y ponderar más las habilidades y valores complejos en la segunda.

\section{La construcción del plan del curso y la distribución del esfuerzo del alumno}

Definida la metodología y el sistema de evaluación, llega el momento de distribuir la carga de trabajo, determinando, de las 450 horas que deben exigirse al alumno para poder superar la materia, cuáles deberán dedicarse a cada actividad, y sobre todo, cuáles deberán hacerse dentro del aula y cuáles fuera ${ }^{14}$.

En la distribución de ese esfuerzo debemos tener presente que de las 450 horas, 300 , las equivalentes a 10 ECTS, corresponderán a la primera parte de la asignatura, mientras que las 150 horas restantes se asignarán a la segunda parte ${ }^{15}$. El resultado del

${ }^{14}$ Esta distribución del esfuerzo entre trabajo presencial y autónomo no resulta sencillo, tal y como pone de manifiesto Menéndez Varela (2009).

15 Se está tomando como definición de ECTS el equivalente a 30 horas de esfuerzo del alumno. 
esfuerzo a realizar dentro y fuera del aula para un adecuado aprovechamiento del curso y un correcto aprendizaje del alumno se recoge en la tabla $3{ }^{16}$.

TABLA 3.- DISTRIBUCIÓN DEL ESFUERZO PRESENCIAL Y AUTÓNOMO DEL ALUMNO POR BLOQUES EN LAS DOS PARTES DE LA MATERIA

\begin{tabular}{|c|c|c|c|c|c|c|c|c|c|}
\hline & \multicolumn{4}{|c|}{ Primer semestre (10 ECTS) } & \multicolumn{4}{|c|}{ Segundo semestre (5 ECTS) } & \multirow[b]{2}{*}{ Total } \\
\hline & Bloque 1 & Bloque 2 & Bloque 3 & Total & Bloque 1 & Bloque 2 & Bloque 3 & Total & \\
\hline Trabajo presencial & 18 & 45,5 & 40,5 & 104 & 12 & 15,5 & 27,5 & 55 & 159 \\
\hline Presentación & 2 & & & 2 & & & & & 2 \\
\hline Lección magistral & & & 2 & 2 & 2 & 2 & 2 & 6 & 8 \\
\hline Seminario & 12 & 33 & 26 & 71 & 6 & 6 & 16 & 28 & 99 \\
\hline Tutoría conjunta & & & & & 2 & 2 & 2 & 6 & 6 \\
\hline Taller & 3 & 4 & 4 & 11 & 2 & 2 & 2 & 6 & 17 \\
\hline Tutoría de seguimiento & & 3 & 3 & 6 & & & & & 6 \\
\hline Conferencia experto & & 2 & & 2 & & & & & 2 \\
\hline Presentación de noticias & & 2 & 2 & 4 & & 2 & 2 & 4 & 8 \\
\hline Prueba parcial & 1 & 1,5 & 1,5 & 4 & & 1,5 & 1,5 & 3 & 7 \\
\hline Prueba Final & & & 2 & 2 & & & 2 & 2 & 4 \\
\hline Trabajo autónomo & 30 & 84 & 82 & 196 & 25 & 28 & 42 & 95 & 291 \\
\hline Lección magistral & & & & & & & & & \\
\hline Seminario & 24 & 63 & 54 & 141 & 18 & 20 & 34 & 72 & 213 \\
\hline Pruebas parciales & 20 & 48 & 44 & 112 & 10 & 10 & 20 & 40 & 152 \\
\hline Libro abierto & & & & & 2 & 2 & & 4 & 4 \\
\hline Prueba final & 4 & 15 & 10 & 29 & 6 & 8 & 14 & 28 & 57 \\
\hline Tutoría conjunta & & & & & & & & & \\
\hline Taller & 6 & 12 & 12 & 30 & 7 & 7 & 7 & 21 & 51 \\
\hline Tutoría de seguimiento & & 4 & 4 & 8 & & & & & 8 \\
\hline Proyecto final & & & 10 & 10 & & & & & 10 \\
\hline Conferencia experto & & 3 & & 3 & & & & & 3 \\
\hline Presentación de noticias & & 2 & 2 & 4 & & 1 & 1 & 2 & 6 \\
\hline Horas totales de esfuerzo & 48 & 129,5 & 122,5 & 300 & 37 & 43,5 & 69,5 & 150 & 450 \\
\hline
\end{tabular}

\section{Fuente: Elaboración propia}

Una vez realizada la distribución del esfuerzo del alumno, es necesario elaborar el plan de curso, que recoge la distribución semanal de la carga de trabajo dentro del aula. Este plan de curso se pasará a la Secretaría de la Facultad, quien recogerá los de cada una de las asignaturas y construirá a partir de ellos, y junto a los coordinadores de curso, los horarios de cada grupo, evitándose así solapamientos y concentraciones de esfuerzos. El plan de curso de nuestra asignatura se recoge en la tabla 4, donde se observa una mayor carga de trabajo en el primer semestre que en el segundo ${ }^{17}$.

${ }^{16}$ El tiempo dedicado a la realización de las pruebas a libro abierto se incluye dentro de los seminarios.

${ }^{17}$ En la tabla no se ha recogido por separado el tiempo dedicado a la presentación de noticias, sino que éste, al estar repartido de forma uniforme a lo largo del curso (aproximadamente 10 minutos semanales hasta que todos los grupos constituidos hayan expuesto), se ha incluido en los tiempos de los seminarios de cada bloque. 
Definidas las competencias, diseñada la metodología, construido el sistema de evaluación, y distribuida la carga de trabajo del alumno, es necesario saber el esfuerzo que va a suponer para el profesor desarrollar esta materia.

Al igual que los alumnos, los miembros de la Unidad Docente deberán realizar un esfuerzo tanto dentro como fuera del aula, correspondiendo las horas de trabajo no presencial a las dedicadas a la preparación de documentación, exámenes y talleres, la corrección de pruebas, y la organización y diseño de la asignatura.

TABLA 4.- PLANIFICACIÓN SEMANAL DE LA MATERIA DISEÑADA

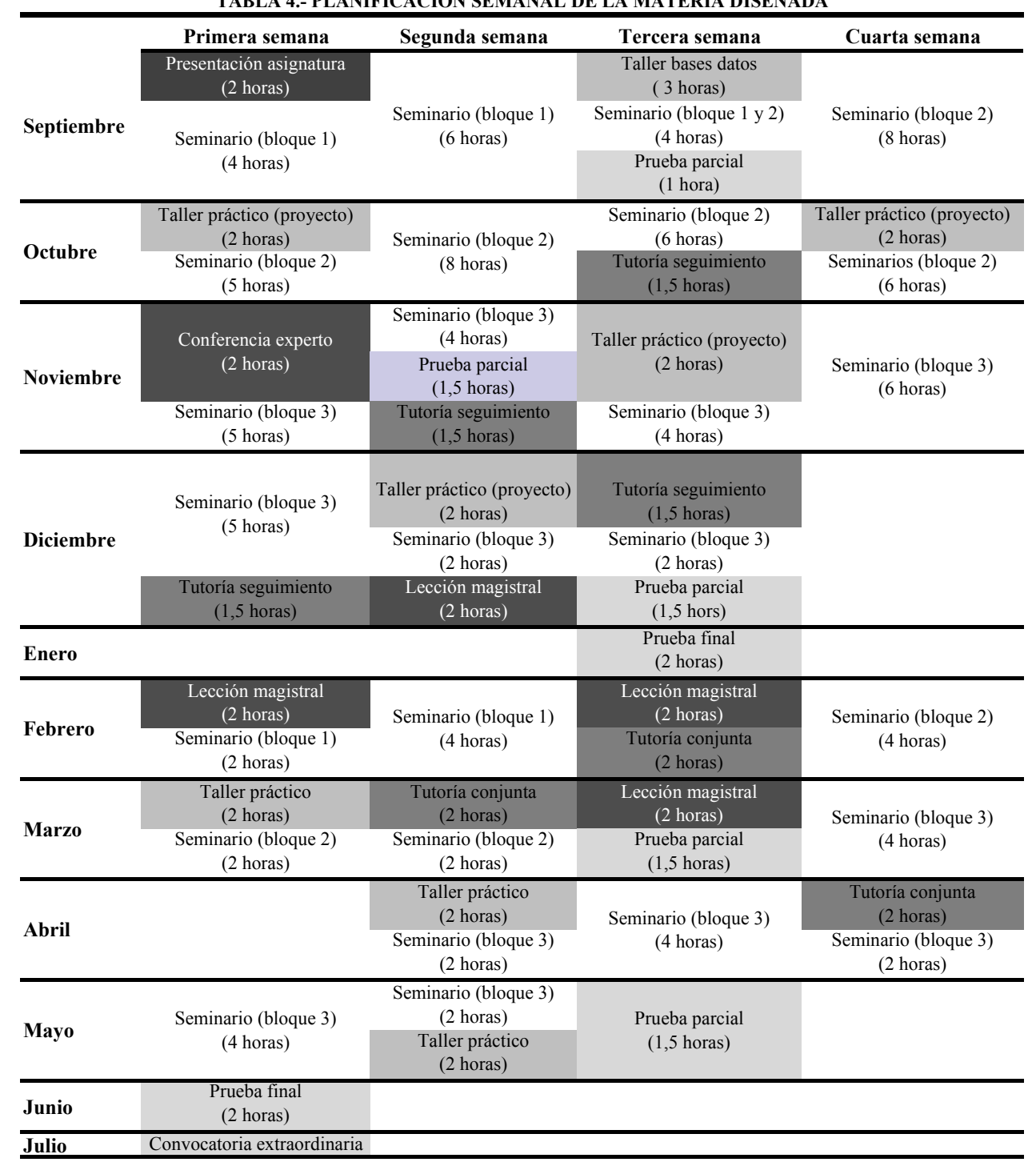

\section{Fuente: Elaboración propia}




\section{Esfuerzo de los miembros de la Unidad Docente}

El concepto de Unidad Docente, y el trabajo conjunto de sus miembros, es esencial para el buen desarrollo de la materia pues, por un lado, existen varias pruebas que son comunes a todos los alumnos, con independencia del profesor que imparta el seminario, y por otro, creemos en la necesidad de contar con un material común mínimo elaborado por todos los integrantes de la Unidad para una adecuada formación del alumno. Además, debemos ser conscientes, de que distribuir la carga de trabajo entre los miembros de la Unidad Docente aligerará las horas que cada profesor deberá dedicar a la asignatura.

TABLA 5.- DISTRIBUCIÓN DEL ESFUERZO MEDIO, PRESENCIAL Y AUTÓNOMO, DE LA UNIDAD DOCENTE

\begin{tabular}{|c|c|c|c|c|c|c|c|c|c|}
\hline & \multicolumn{4}{|c|}{ Primer semestre (10 ECTS) } & \multicolumn{4}{|c|}{ Segundo semestre (5 ECTS) } & \multirow[b]{2}{*}{ Total } \\
\hline & Bloque 1 & Bloque 2 & Bloque 3 & Total & Bloque 1 & Bloque 2 & Bloque 3 & Total & \\
\hline Trabajo presencial & 19 & 57,5 & 50,5 & 127 & 16 & 19,5 & 31,5 & 67 & 194 \\
\hline Presentación & 2 & & & 2 & & & & & 2 \\
\hline Lección magistral & & & 2 & 2 & 2 & 2 & 2 & 6 & 8 \\
\hline Seminario & 12 & 33 & 26 & 71 & 6 & 6 & 16 & 28 & 99 \\
\hline Tutoría conjunta & & & & & 2 & 2 & 2 & 6 & 6 \\
\hline Taller & 6 & 8 & 8 & 22 & 6 & 6 & 6 & 18 & 40 \\
\hline Tutoría de seguimiento & & 9 & 9 & 18 & & & & & 18 \\
\hline Conferencia experto & & 2 & & 2 & & & & & 2 \\
\hline Presentación de noticias & & 2 & 2 & 4 & & 2 & 2 & 4 & 8 \\
\hline Prueba parcial & 1 & 1,5 & 1,5 & 4 & & 1,5 & 1,5 & 3 & 7 \\
\hline Prueba Final & & & 2 & 2 & & & 2 & 2 & 4 \\
\hline Trabajo no presencial & 32,75 & 77,5 & 115,5 & 221,8 & 22 & 53,5 & 84 & 159,5 & 381,3 \\
\hline Presentación & 0,25 & & & 0,25 & & & & & 0,25 \\
\hline Lección magistral & & & 1 & 1 & 1 & 1 & 1 & 3 & 4 \\
\hline Preparación seminarios & 6,5 & 20,5 & 18,5 & 45,5 & 5,5 & 7 & 15,5 & 28 & 73,5 \\
\hline Clases & 6 & 20 & 15 & 41 & 4 & 5 & 12 & 21 & 62 \\
\hline Pruebas parciales & 0,5 & 0,5 & 0,5 & 1,5 & & 0,5 & 0,5 & 1 & 2,5 \\
\hline Libro abierto & & & & & 1,5 & 1,5 & & 3 & 3 \\
\hline Prueba final & & & 3 & 3 & & & 3 & 3 & 6 \\
\hline $\begin{array}{l}\text { Corrección seminarios } \\
\text { Clases }\end{array}$ & 10 & 15 & 25 & 50 & 2 & 17 & 24 & 43 & 93 \\
\hline Pruebas parciales & 10 & 15 & 15 & 40 & & 15 & 15 & 30 & 70 \\
\hline Libro abierto & & & & & 2 & 2 & & 4 & 4 \\
\hline Prueba final & & & 10 & 10 & & & 9 & 9 & 19 \\
\hline Tutoría conjunta & & & & & 2,5 & 8,5 & 8,5 & 19,5 & 19,5 \\
\hline Preparación & & & & & 2 & 8 & 8 & 18 & 18 \\
\hline Corrección & & & & & 0,5 & 0,5 & 0,5 & 1,5 & 1,5 \\
\hline Taller & 12 & 30 & 30 & 72 & 10 & 16 & 16 & 42 & 114 \\
\hline Preparación & 2 & 6 & 6 & 14 & 2 & 4 & 4 & 10 & 24 \\
\hline Corrección & 10 & 24 & 24 & 58 & 8 & 12 & 12 & 32 & 90 \\
\hline Tutoría de seguimiento & & 2 & 2 & 4 & & & & & 4 \\
\hline Proyecto final (corrección) & & & 15 & 15 & & & & & 15 \\
\hline Conferencia experto (corrección) & & 5 & & 5 & & & & & 5 \\
\hline Presentación de noticias & & 1 & 1 & 2 & & 1 & 1 & 2 & 4 \\
\hline Reuniones de coordinación & 4 & 4 & 6 & 14 & 1 & 3 & 6 & 10 & 24 \\
\hline Horas totales de esfuerzo & 53,75 & 133 & 162 & 348,8 & 38 & 73 & 115,5 & 226,5 & 575,3 \\
\hline
\end{tabular}

Fuente: Elaboración propia 
El esfuerzo a realizar va a depender de varios factores, entre ellos: el número de alumnos matriculados; los profesores, incluidos becarios, que integren la Unidad Docente; así como de los talleres ofertados y el número máximo de alumnos participantes en ellos. Para ofrecer un cálculo de este esfuerzo, supondremos que la Unidad Docente cuenta con cinco profesores y dos becarios que realizarán algún taller en el segundo semestre y algunas tutorías de seguimiento en el primero. Por otro lado, consideraremos que el número de alumnos por grupo de seminario se sitúa en torno a los 30, y que el número de grupos totales es de 10 (por tanto, 300 alumnos en la materia), correspondiendo dos grupos de seminario a cada profesor, lo que obliga a multiplicar las horas de esfuerzo presencial por dos con la excepción de las pruebas comunes. Además, hay que considerar el desdoble de los grupos en los talleres y tutorías, lo que eleva la carga presencial de esas actividades.

De la tabla 5, donde se recoge esta distribución, se concluye que el esfuerzo que deben hacer los profesores, medido en horas de trabajo, para lograr un adecuado aprendizaje de competencias en el alumno, es superior al que deben realizar éstos, por lo que el trabajo en equipo dentro de la Unidad Docente resulta esencial. Además, de un año para otro, el tiempo exigido para la preparación de la asignatura se reducirá, pues se parte de un material ya construido al que sólo será necesario incorporar mejoras y actualizaciones.

\section{Conclusiones}

El diseño de una materia de los Grados de Economía y Empresa, tal y como se describe en el artículo exige, de los profesores que imparten una misma asignatura, en primer lugar, una reflexión profunda sobre las competencias que podrán desarrollarse de manera clara en el alumno, la metodología de trabajo más adecuada, y el sistema de evaluación que deberá emplearse, y en segundo, una fuerte coordinación entre los diferentes aspectos que deben incluirse en la guía docente.

Si bien, el hecho de que con Bolonia sea imprescindible cubrir unas competencias que se definen en función del perfil de alumno que se desea, hace que se deba dar un paso más, requiriendo una estrecha conexión entre las competencias y los sistemas de evaluación empleados en las diferentes asignaturas, materias y cursos. En este sentido, es necesario contar con coordinadores de titulación que garanticen una correcta definición del grado de desarrollo de las competencias que se irán alcanzando en cada curso, con coordinadores de área que ayuden a lograr el acoplamiento de las diferentes materias, así como con coordinadores de curso que favorezcan el ensamblaje entre las unidades docentes.

La coordinación y planificación deben imponerse, y ser la base en el diseño de la materia, el área, el curso y la titulación. 


\section{Referencias bibliográficas}

BENITO, A. Y CRUZ, A. (2005), Nuevas claves para la docencia universitaria, Ed. Narcea, Madrid.

BIGGS, J. (2006), Calidad del aprendizaje universitario. Ed. Narcea, Madrid.

BROWN, S. Y GLASNER, A. (2007), Evaluar en la universidad: problemas y nuevos enfoques, ( $2^{\mathrm{a}}$ edición), Ed. Narcea, Madrid.

CALVO BERNARDINO, A. Y MINGORANCE ARNÁIZ, A.C. (2009), "La estrategia de las Universidades frente al Espacio Europeo de Educación Superior", Revista Complutense de Educación, Vol. 20, n 2 2, pp. 319-342.

(http://revistas.ucm.es/index.php/RCED/article/view/RCED0909220319A/15299)

CALVO BERNARDINO, A., Y MINGORANCE ARNÁIZ, A.C. (2011), "Valoración universitaria de la formación de competencias: El esfuerzo y la satisfacción de los estudiantes", Revista de Educatio Siglo XXI, vol 29.2, pp. 283-312.

(http://revistas.um.es/educatio/article/view/133071/122771)

CLIMENT, J.B. (2010), "Reflexiones sobre la educación basada en competencias", Revista Complutense de Educación, vol. 21, n 1, pp. 91-106.

(http://revistas.ucm.es/index.php/RCED/article/viewFile/RCED1010120091A/1520 5)

DELGADO, A.Ma'. Y OLIVER, R. (2006), "La evaluación continua en un nuevo escenario docente", Revista de Universidad y Sociedad del Conocimiento, Vol 3, $\mathrm{n}^{\mathrm{o}}$ 1 , páginas 13 .

(http://umd.upla.cl/cursos/fmdelbuey/procesos_instruccion_aprendizaje/evaluacion continua.pdf)

ESTEVE PARDO, $\mathrm{M}^{\mathrm{a}}$.L. (2008), Papel y relevancia de la figura del coordinador de curso en los nuevos sistemas docentes, Ed. Instituto de Ciencias de la Educación Josep Pallach de la Universidad de Gerona, Gerona. (http://hdl.handle.net/10256/860)

FERNÁNDEZ MARCH, A. (2005), Nuevas metodologías docentes, Ed. Instituto de Ciencias de la Educación de la Universidad Politécnica de Valencia, Valencia.

(http://www.upm.es/innovacion/cd/02_formacion/talleres/nuevas_meto_docent/nue vas_metodologias_docentes_2.pdf)

----- (2006), "Metodologías activas para la formación de competencias". Educatio siglo $X X I, \mathrm{n}^{\mathrm{o}} 24$, pp. 35-56. (http://revistas.um.es/educatio/article/view/152/135)

FULLANA, J. (coord.) (2009), Guia per a l'avaluació de competències en Educació Social, Ed. AQU Catalunya, Barcelona. (http://www.aqu.cat/doc/doc_35616841_1.pdf)

GINÉ, N. (coord.) (2009), “Aplicación de la carpeta de aprendizaje en la universidad”, Cuaderno de docencia universitaria, $n^{\circ} 10$, Ed. Octaedro del Instituto de Ciencias 
de la Educación de la Universidad de Barcelona, Barcelona. (http://octaedro.com/pdf/16510.pdf)

MAYOR RUÍZ, C. (2009), "Nuevos retos para una Universidad en proceso de cambio: ¿Pueden ser los profesores principiantes los protagonistas?", Profesorado. Revista de Currículum y Formación del Profesorado, Vol 13, $\mathrm{n}^{\circ}$ 1, pp 61-77. (http://www.ugr.es/ recfpro/rev131ART4.pdf)

MENÉNDEZ VARELA, J.L. (2009), "La aplicación del Sistema Europeo de Transferencia y Acumulación de Créditos. Consideraciones sobre la noción de carga de trabajo y los procedimientos de cálculo", Revista Complutense de Educación, vol. 20, nº 2, pp. 381-401.

(http://revistas.ucm.es/index.php/RCED/article/view/RCED0909220381A/15325)

MORENO, M.V., QUESADA, C. Y PINEDA, P. (2010), "El grupo de trabajo como método innovador de formación del profesorado para potenciar la transferencia del aprendizaje", Revista Española de Pedagogía, no 246, mayo-agosto, pp 281-296.

PALLISERA DÍAZ, M.; FULLANA NOELL, J.; PLANAS LLADO, A. Y VALLE GÓMEZ, A. (2010), "La adaptación al Espacio Europeo de Educación Superior en España: los cambios/retos que implica la enseñanza basada en competencias y orientaciones para responder a ello", Revista Iberoamericana de Educación, Vol 52, $\mathrm{n}^{\circ} 4,13$ páginas.

(http://www.rieoei.org/deloslectores/3250Diaz.pdf)

PARCERISA ARAN, A. (2008), "Plan docente: planificar las asignaturas en el marco europeo de educación superior", Cuadernos de docencia universitaria, $n^{\circ} 1$, Ed. Octaedro del Instituto de Ciencias de la Educación de la Universidad de Barcelona, Barcelona.

(http://www.octaedro.com/ice/pdf/DIG101.pdf)

RODRÍGUEZ IZQUIERDO, Ma.R. (2008): "Un modelo de formación basado en las competencias: hacia un nuevo paradigma en la enseñanza universitaria", Contextos Educativos, $\mathrm{n}^{\circ} 11$, pp 131-147.

(http://www.unirioja.es/servicios/sp/ej/contextos/con11.shtml)

VILlA, A. Y POBLETE, M. (2006). Aprendizaje basado en competencias. Una propuesta para la evaluación de las competencias genéricas, Ed. Vicerrectorado de Innovación y Calidad de la Universidad de Deusto con la colaboración del ICE, Bilbao.

VV.AA. (2011), "Necesidades de formación del profesorado universitario para la adaptación de su docencia al Espacio Europeo de Educación Superior", Relieve, Vol. 17, $\mathrm{n}^{\mathrm{o}} 1$, pp 1-22.

(http://www.uv.es/RELIEVE/v17n1/RELIEVEv17n1_1.htm)

YÁNIZ ÁlVAREZ DE EULATE, C. Y VILLARDÓN, L. (2006), "Planificar desde competencias para promover el aprendizaje", Cuadernos del Instituto de Ciencias de la Educación $n^{\circ} 12$ de la Universidad de Deusto, Bilbao. 


\section{Correspondencia con los autores}

Antonio CALVO-BERNARDINO

Departamento de Economía Aplicada

Universidad CEU San Pablo

Julián Romea no 23; Madrid 28003

Correo-e: acalvo@ceu.es

Ana Cristina MINGORANCE-ARNÁIZ

Departamento de Economía Aplicada

Universidad CEU San Pablo

Julián Romea n 23; Madrid 28003

Correo-e: mingor.fcee@ceu.es 